OPEN ACCESS

Edited by:

Andrei Mocan,

Iuliu Hațieganu University of Medicine and Pharmacy, Romania

Reviewed by:

Víctor López,

Universidad San Jorge, Spain Luigi Menghini,

University "G. d'Annunzio" of Chieti-

Pescara, Italy

*Correspondence:

Mario Simirgiotis

mario.simirgiotis@uach.cl

Javier Echeverría

javier.echeverriam@usach.cl

Specialty section:

This article was submitted to

Ethnopharmacology,

a section of the journal

Frontiers in Pharmacology

Received: 13 March 2020

Accepted: 11 May 2020

Published: 27 May 2020

Citation:

Barrientos $R$

Fernández-Galleguillos C, Pastene E,

Simirgiotis M, Romero-Parra J,

Ahmed S and Echeverría J (2020)

Metabolomic Analysis, Fast

Isolation of Phenolic Compounds,

and Evaluation of Biological Activities

of the Bark From Weinmannia

trichosperma Cav. (Cunoniaceae).

Front. Pharmacol. 11:780.

doi: 10.3389/fphar.2020.00780

\section{Metabolomic Analysis, Fast Isolation of Phenolic Compounds, and Evaluation of Biological Activities of the Bark From Weinmannia trichosperma Cav. (Cunoniaceae)}

\author{
Ruth Barrientos ${ }^{1}$, Carlos Fernández-Galleguillos ${ }^{1}$, Edgar Pastene ${ }^{2}$, Mario Simirgiotis ${ }^{1 *}$, \\ Javier Romero-Parra ${ }^{3}$, Shakeel Ahmed ${ }^{1}$ and Javier Echeverría ${ }^{4 *}$ \\ ${ }^{1}$ Instituto de Farmacia, Facultad de Ciencias, Universidad Austral de Chile, Valdivia, Chile, ${ }^{2}$ Laboratorio de Sintesis y \\ Biotransformación de Productos Naturales, Departamento de Ciencias Básicas, Facultad de Ciencias, Universidad del \\ Bío-Bío, Chillán, Chile, ${ }^{3}$ Departamento de Química Orgánica y Fisicoquímica, Facultad de Ciencias Químicas y \\ Farmacéuticas, Universidad de Chile, Santiago, Chile, ${ }^{4}$ Departamento de Ciencias del Ambiente, Facultad de Química y \\ Biología, Universidad de Santiago de Chile, Santiago, Chile
}

Weinmannia trichosperma Cav. (Cunoniaceae) (local name, tineo; Mapuche names, madén, mëdehue) is an endemic species of Chile and Argentina used in Mapuche traditional medicine in the treatment of chronic diarrhea, inflammation, and wound healing. This study focused on the isolation, analysis, and characterization of the biological activity of compounds and bark extracts from this plant for the first time. The infusion and tincture of the bark were characterized regarding antioxidant and important enzyme inhibitory activities, phenolics, and flavonoids content and UHPLC-ESI-OT-MS metabolite profiling. Twenty-five metabolites were detected in the medicinal infusion of $W$. trichosperma, three flavonols were isolated: isoastilbin, neoisoastillbin, and neoastilbin ((2R,3S)-, $(2 S, 3 R)$-, and (2S,3S)-dihydroquercetin 3-O-alpha-L-rhamnoside) by countercurrent chromatography, and the isomers were quantified in the bark using a validated analytical HPLC methodology. The antioxidant properties were measured by ABTS, DPPH, FRAP, ORAC, and TEAC methods. The infusion displayed a strong DPPH and ABTS scavenging activity $\left(\mathrm{IC}_{50}=20.58\right.$ and $3.070 \mu \mathrm{g} \mathrm{ml}^{-1}$, respectively) while a moderated effect was observed in the FRAP, ORAC, and ABTS assays. The infusion showed a content of phenolic and flavonoid compounds of $442.1 \mathrm{mg} \mathrm{GAE} \mathrm{g}^{-1}$ and 15.54 mg QE $\mathrm{g}^{-1}$, respectively. Furthermore, the infusion showed a good and promissory inhibitory activity $(33.80 \%, 33.12 \%$, and $82.86 \%$ for AChE, BuChE, and 5-hLOX, respectively) and isoastilbin (51.70\%, 50.10\%, and 34.29-80.71\% for AChE, BuChE, and 5-hLOX, respectively). The biomolecules identified in this study support the traditional uses of this bark and the potential industrial interest from this Valdivian plant species.

Keywords: Weinmannia trichosperma, tineo, astilbin, traditional medicine, HPLC-MS, centrifugal partition chromatography 


\section{INTRODUCTION}

Weinmannia trichosperma Cav. (Cunoniaceae) (local name: tineo, Mapuche name: madén, mëdehue, Figure 1) is an evergreen tree endemic of temperate rainforest of Chile and Argentina. In Chile, this plant grows in the regions of Maule, Biobío, Araucanía, Los Ríos, Los Lagos, Aysén, and Magallanes (Rodriguez et al., 2018). The local inhabitants use the bark infusion of $W$. trichosperma to treat chronic diarrhea, and it is used as poultice for application on wounds (Gusinde, 1936; Muñoz et al., 1981; Houghton and Manby, 1985). Previous pharmacological studies of $W$. trichosperma have demonstrated their antimicrobial potential (Mølgaard et al., 2011), and one quantitative phytochemical study showed that the composition of tannins and phenolic compounds of this bark were $19.98 \%$ and $4.81 \%$, respectively (Holler et al., 2012). Extracts of natural products are highly complex mixtures of active compounds, and the purification is a challenging task (Skalicka-Woźniak and Garrard, 2014). Among the chemical methods for the study of plants, chromatographic analysis has a fundamental role because it involves numerous advantages, such as its specificity and the possibility of qualitative and quantitative analyses (Kowalska et al., 2007). The interest in endemic traditional plants is important since they represent a huge source very little explored of potential biomolecules that can become potential promising candidates for the study of new drugs of pharmacological interest and support the use of native species in functional foods or nutraceuticals. Ultra-high-performance chromatography (UHPLC) coupled to mass spectrometer (MS)

Abbreviations: AAPH, 2,2'-Azobis(2-amidinopropane) dihydrochloride; ABTS, 2,2'-Azino-bis(3-ethylbenzothiazoline-6-sulfonic acid); AChE, Acetylcholinesterase; ANOVA, One-way analysis of variance; ATCI, Acetylthiocholine iodide; AUC, Area under curve; BChE, Butyrylcholinesterase; BK, Bradykinin; BTC1, Butyryl-thiocholine chloride; CCC, Counter-current chromatography; COX, Cyclooxygenase; CPC, Centrifugal partition chromatography; CT, Cycle time; DPPH, 2,2,1-diphenyl-1-picrylhydrazyl; DTNB, 5-dithio-bis(2-nitrobenzoic) acid; ESI, Electrospray ionization; f3, Fluorescence reading at cycle 3; FL, Fluorescein disodium; Fn, Fluorescence reading at cycle $n$; FRAP, Ferric Reducing Antioxidant Power; FWHM, Full width at half maximum; GAE, Gallic acid equivalent; h5-LOX, Human 5lipoxygenase; HAT, Histone acetyltransferases; HEPES, (4-(2-hydroxyethyl)-1piperazineethanesulfonic acid); HEMWAT, Hexane-ethyl acetate-methanol-water system; HSD, Honestly significant difference; $\mathrm{IC}_{50}$, Half maximal inhibitory concentration; ICAM-1, Intercellular adhesion molecule-1; ICH, International Council for Harmonization of Technical Requirements for Pharmaceuticals for Human Use; IL-1 $\beta$, Interleukin-1 $\beta$; IL-6, Interleukin-6; iNOS, Inducible Nitric Oxide Synthase; $k$, Partition coefficient; LOD, Limit of detection; LOQ, Limit of quantification; MAPK, mitogen-activated protein kinase; MMP, Matrix Metalloproteinase; MS, mass spectrometry; NF- $k$ B, Nuclear factor kappa-lightchain-enhancer of activated B cells; NLRP3, NLR Family Pyrin Domain Containing 3; NO, Nitric oxide; ORAC, Oxygen radical absorbance capacity; OT, Orbitrap technology; PAF, Platelet activating factor; PBMC, Human peripheral blood mononuclear cells; PDA, Photodiode Array Detection; PTFE, Polytetrafluoroethylene; QE, Quercetin equivalent; ROS, Reactive oxygen species; $\mathrm{RP}$, Reverse phase; RSD, Relative standard deviation; SD, Standard deviation; SP, Substance P; TE, Trolox equivalents; TEAC, Trolox equivalent antioxidant capacity; TFC, Total Flavonoid Content; TIC, Total Ion Chromatogram; TNF$\alpha$, Tumour Necrosis Factor alpha; TPC, Total Phenolic Content; TPTZ, 2,4,6-tri (2-pyridyl)-s-triazine; Trolox, 6-hydroxy-2,5,7,8-tetramethylchromane-2carboxylic acid; UV, Ultraviolet; UHPLC, Ultra high performance chromatography; VCAM-1, Vascular cell adhesion molecule 1.

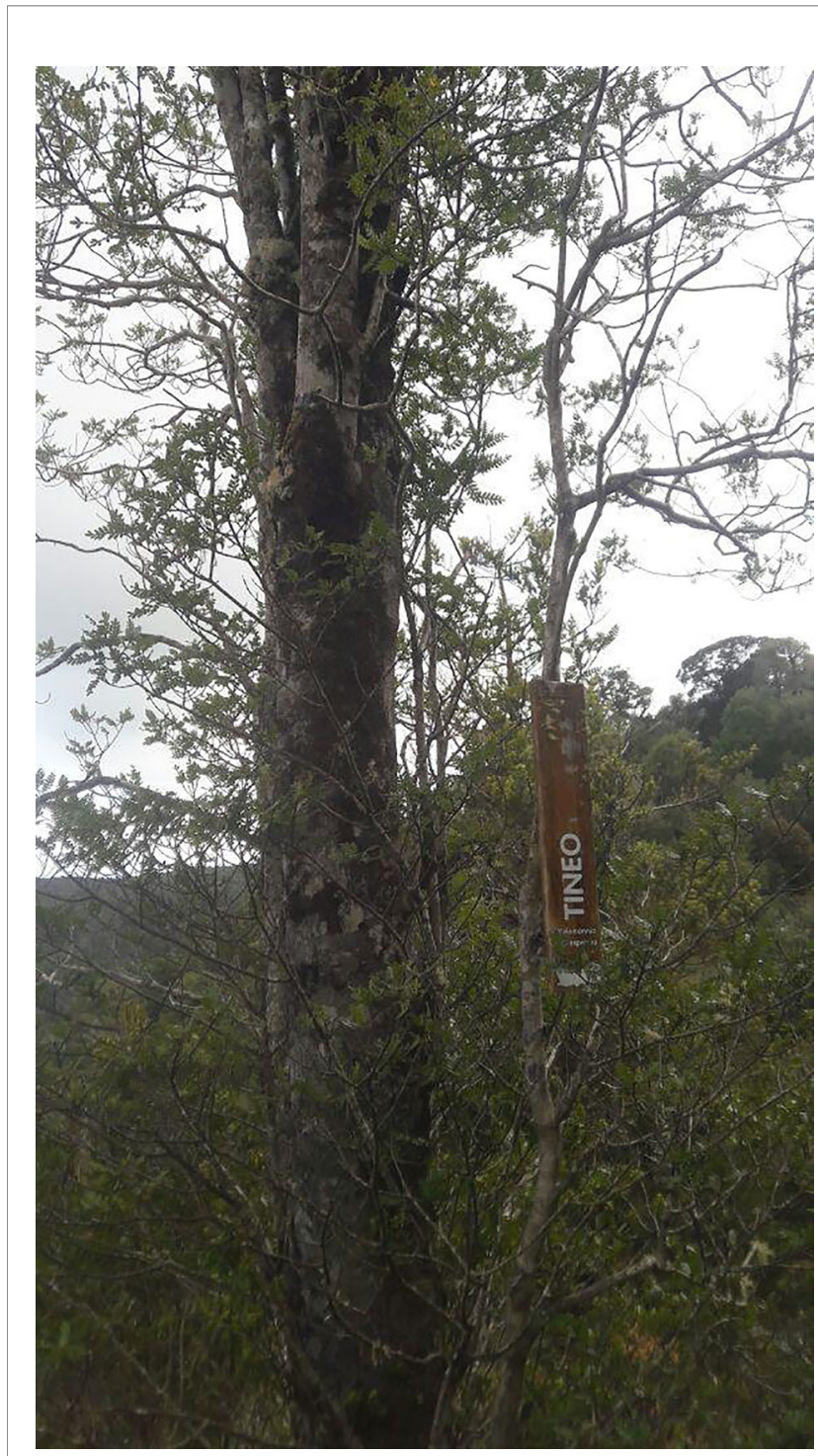

FIGURE 1 | Picture of W. trichosperma taken in March 2017 in Parque Oncol, Valdivia.

hyphenated devices nowadays offer higher sample throughput with more accurate information per sample. In the case of orbitrap technology (OT), it offers the fast and reliable untargeted information of several different metabolites, such as phospholipids, glycans, phenolic compounds, peptides, pesticides, toxins, and other small bioactive molecules (Simirgiotis et al., 2016; Luna et al., 2018; Deng et al., 2019, Yang et al., 2018a). To our knowledge, there are no reports on chemical characterization, antioxidant, antiinflammatory, or enzyme inhibitory capacities of the phenolic-enriched bark obtained from $W$. trichosperma.

Centrifugal partition chromatography (CPC) (Ito, 2005) is a very versatile technique that has been used for decades as a fractionation technique, and nowadays, most of the applications are dedicated to the investigation of medicinal plants and 
isolation of natural products (Marston and Hostettmann, 2006; Friesen et al., 2015; Liu et al., 2015).

In this work, we have applied CPC for the fast isolation of the main phenolic constituents from bark of $W$. trichosperma. Additionally, an UHPLC-PDA-MS fingerprint was obtained, and the main compounds were quantified in the medicinal bark. Furthermore, the antioxidant, anti-inflammatory, and enzyme inhibitory effects complemented with the full polyphenolic profile are performed, supporting the reputed medicinal properties of this plant and showing the presence of molecules of pharmacological and industrial interest.

\section{MATERIALS AND METHODS}

\section{Chemical and Reagents}

Gallic acid (purity $>98 \%$ ), quercetin, (purity $>97 \%$ ), 6-hydroxy2,5,7,8-tetramethylchromane-2-carboxylic acid (Trolox) (purity > 97\%), 2,2'-azinobis(3-ethylbenothiazoline-6-sulfonic acid) diammonium salt (ABTS), 2,2-diphenyl-1-picrylhydrazyl (DPPH), Folin-Ciocalteu reagent 2,4,6-tri(2-pyridyl)-s-triazine (TPTZ), aluminum chloride, iron (III) chloride hexahydrate, (4(2-hydroxyethyl)-1-piperazineethanesulfonic acid (HEPES), ethylenediaminetetraacetic acid (EDTA), adenosine 5' triphosphate (ATP) disodium salt, acetylcholinesterase from Electrophorus electricus (electric eel) and butyrylcholinesterase from equine serum were from Sigma-Aldrich ${ }^{\circledR}$ (Chile). The enzyme 5-lipoxygenase (human, recombinant) were from Cayman Chemical (Item No. 60402). Calcium chloride, sodium carbonate, sodium hydroxide, sodium nitrite, and potassium persulphate were obtained from Merck $^{\circledR}$ (Chile). Acetone, galanthamine, zileuton, sodium acetate trihydrate, and glacial acetic acid were from Merck ${ }^{\circledR}$ (Chile). HPLC reagents, formic acid, methanol, ultrapure water, ethyl acetate, and $n$-hexane were form Merck ${ }^{\circledR}$ (Chile). Deionized water was used for all the experiments.

\section{Plant Material}

The bark of $W$. trichosperma was collected during the months of October and November of 2017 in Valdivia, XIV Region de Los Ríos, Chile, and deposited in our laboratory herbarium (voucher number Wt10012017). The plant was identified by the botanist Alicia Marticorena.

\section{Extraction of Plant Material}

Once the plant material was collected, it was cleaned, dried, and stored at room temperature for 7 days. Then, the bark was cut into pieces and ground to powder in a mill. To obtain the ethanolic extract, or tincture, three macerations were carried out with $540 \mathrm{~g}$ of bark powder, $2 \mathrm{~L}$ of absolute ethanol, and macerated for $24 \mathrm{~h}$ (three times) in darkness at room temperature. Then, the extract was filtered and concentrated in a rotary evaporator to dryness (at $40^{\circ} \mathrm{C}$, at 2.7 Bar and 80 r.p.m.), finally, the extract was stored at $-80^{\circ} \mathrm{C}$ in a $50-\mathrm{ml}$ glass bottle. To obtain the edible infusion, $2.5 \mathrm{~g}$ of plant material were weighed then $250 \mathrm{ml}$ of boiling deionized water was added, without

stirring, to prepare a cup-of-tea infusion of $W$. trichosperma, then it was allowed to stand for $1 \mathrm{~h}$ at room temperature and filtered under vacuum, after that the infusion was frozen at $-42^{\circ} \mathrm{C}$, and finally lyophilized and stored at $-80^{\circ} \mathrm{C}$ in a $1-$ to 5-ml glass bottle.

\section{Centrifugal Partition Chromatography Selection of the Solvent System}

Centrifugal partition chromatography was applied for the rapid isolation of the main phenolic compounds present in the bark of $W$. trichosperma. The biphasic solvent system used to perform the isolation of the compounds was selected by measuring the partition coefficient $(k)$ in different proportions of the hexaneethyl acetate-methanol-water system (HEMWAT). The value of $k$ was defined for the main phenolic compound of the extracts of $W$. trichosperma as $k=\mathrm{A}_{\text {upper }} / \mathrm{A}_{\text {lower }}$, where $\mathrm{A}_{\text {upper }}$ corresponds to the area under the curve of the peak in the upper phase and $A_{\text {lower }}$ corresponds to the area under the curve of the peak in the lower phase of the solvent system, these areas were obtained by gradient elution (Table 1), using HPLC-PDA with detection wavelengths at $230,290,330$, and $380 \mathrm{~nm}$ with a flow of $1 \mathrm{ml} \mathrm{min} \mathrm{mi}^{-1}$ at $25^{\circ} \mathrm{C}$. To obtain the $\mathrm{k}$ value, approximately $10 \mathrm{mg}$ of ethanolic extract were weighed in a $2-\mathrm{ml}$ vial, and $1 \mathrm{ml}$ of upper phase and $1 \mathrm{ml}$ of lower phase of the pre-equilibrated biphasic solvent system (HEMWAT 1: 9: $1: 9 \mathrm{v} / \mathrm{v}, 1: 3: 1: 3 \mathrm{v} / \mathrm{v}, 2: 5: 2: 5 \mathrm{v} / \mathrm{v}$, and $4: 6: 4: 6 \mathrm{v} / \mathrm{v})($ Ito, 2005) were added, vortexed, and filtered using a $0.22-\mu \mathrm{m}$ PTFE filter. Then, $10 \mathrm{ml}$ of each phase was injected in the HPLC-DAD in triplicate to measure the area of each compound. Finally, the biphasic solvent system suitable for the separation of the phenolic compounds of $W$. trichosperma selected.

\section{Separation and Purification of Phenolic Compounds}

The biphasic system HEMWAT 1:9:1:9 v/v was used, and $11 \mathrm{~g}$ of ethanolic extract were weighed and dissolved in a mixture of $5 \mathrm{ml}$ of upper phase and $5 \mathrm{ml}$ of lower phase, sonicated for $5 \mathrm{~min}$ and vortexed for $5 \mathrm{~min}$. The CPC equipment was purged for $1 \mathrm{~min}$ with a flow of $30 \mathrm{ml} \mathrm{min}{ }^{-1}$, the equipment was filled with stationary phase in normal (or ascending) mode with a rotation of $500 \mathrm{rpm}$. Once the CPC equipment rotor had a speed of 1800 r.p.m. manual injection of the sample was performed using the injection loop. The mobile phase was supplied using two HPLC pumps with a flow rate of $10 \mathrm{ml}$ $\min ^{-1}$. The equipment had a PDA detector for the detection of the peaks, the wavelengths used were 280, 330, 350, and $254 \mathrm{~nm}$, the eluent was collected for $1 \mathrm{~h}$ by means of an automatic fraction collector for test tubes (25 ml each). Finally, the extrusion was carried out for $15 \mathrm{~min}$ with a $100 \%$ stationary phase, and the

TABLE 1 | Partition coefficient of different solvents systems (HEMWAT).

Solvent system

HEMWAT (v/v)

$1: 9: 1: 9$

$1: 3: 1: 3$

2:5:2:5

$4: 6: 4: 6$
Partition coefficient $(k) \pm S D$ $(n=3)$

$1,550 \pm 0,090$

$0,425 \pm 0,080$

$0,371 \pm 0,102$

$0,054 \pm 0,025$ 
fractions obtained from the majority compounds were lyophilized and subsequently stored in 15-ml glass bottles.

\section{HPLC Quantitative Analysis}

An HPLC-PDA (Thermo Scientific Dionex Ultimate 3000 Series RS, Thermo Fisher Scientific, Germany) was used to determine and quantify the major compounds in the extracts of $W$. trichosperma. A Purosphere Merck ${ }^{\circledR}$ C18-RP column, $25 \mathrm{~cm}$ long, particle size $2.5 \mu \mathrm{m}$ with a precolumn was used, and an elution gradient of water with formic acid $(1 \% \mathrm{v} / \mathrm{v})$ and methanol with formic acid $(1 \% \mathrm{v} / \mathrm{v})$ was used at a flow rate of $1 \mathrm{ml} \mathrm{min} \mathrm{m}^{-1}$, injection volume of $20 \mu \mathrm{l}$, and UV detection wavelengths of 230, 290, 330, and $380 \mathrm{~nm}$. Elution gradient of A (water with $1 \% \mathrm{v} / \mathrm{v}$ formic acid) and B (methanol with $1 \% \mathrm{v} / \mathrm{v}$ formic acid). The step gradient was as follows: 0 to 8 min linear increase from $10 \%$ to $32 \% \mathrm{~B}$; then maintaining $32 \% \mathrm{~B}$, from 8 to $25 \mathrm{~min}$, then, linear increase to $70 \% \mathrm{~B}$ and coming back to initial conditions, then hold $15 \mathrm{~min}$ for the next injection. The quantification experiments were performed by HPLC-PDA and elution conditions of qualitative analysis (Supplementary Material, Figures S1 and S2). The content of isoastilbin compound and its derivatives were established with reference to calibration curves built with the pure compounds, (astilbin, neoastilbin, and neoisoastilbin) at $254 \mathrm{~nm}$. A stock solution of $2 \mathrm{mg} \mathrm{ml}^{-1}$ of purified compounds was used, and the dilutions were prepared to perform calibration curves with the following concentration levels: $1,5,10,30,50 \mu \mathrm{g} \mathrm{ml}^{-1}$. These dilutions were prepared in triplicate and measured in triplicate $(n=9)$. With the obtained data, the linear regression curve was generated using the Chromeleon 7.2 software, the equation of the curve and the coefficient of determination were obtained (for neoastilbin $\mathrm{y}=$ $571.2372 \mathrm{x}-2.3871, \mathrm{R}^{2}=0.9998$; for isoastilbin $\mathrm{y}=571.6340 \mathrm{x}-$ $2.4065, \mathrm{R}^{2}=0.9997$, and for neoisoastilbin $\mathrm{y}=571.0794 \mathrm{x}-2.3264$, $\left.\mathrm{R}^{2}=0.9998\right)$. All injections were performed in triplicate, and the results were expressed as mean \pm standard deviation (SD).

\section{MS Conditions}

Untargeted analysis of all compounds was performed using a Thermo Scientific Dionex Ultimate 3000 Series RS coupled to an Q-Exactive focus mass spectrometer (Thermo Fisher Scientific, Germany) operated both in positive and negative modes at 17.500 FWHM $(m / z 200)$ using a scan range of $m / z 130-1000$ and injection time of $200 \mathrm{~ms}$ and automatic gain control at $3 \mathrm{e}^{6}$. Scan rate was set at 2 scans s ${ }^{-1}$, and a mass tolerance window was set to $5 \mathrm{ppm}$. The calibration was performed by positive and negative modes before each series of samples. In addition to the full scan mode, for confirmatory purposes, a targeted MS/MS analysis was performed using the mass inclusion list and expected retention times of the target analytes, with a 30-s time window. Data acquired were finally evaluated by the Browser Xcalibur 2.3 (Thermo Fisher) (Nwokocha et al., 2017).

\section{Method Performance and Validation of the Analytical Methodology for HPLC-PDA}

The validation of the analytical methodology was carried out according to the analytical performance parameters suggested by the ICH (International Council for Harmonization of Technical
Requirements for Pharmaceuticals for Human Use) in the guide Q2 (R1) (Borman and Elder, 2018). The accuracy was determined in terms of percent recovery for three points of the calibration curve: 10,50 , and $500 \mu \mathrm{g} \mathrm{ml}^{-1}$. The accuracy was assured for the limit of quantification. In addition, the percentage of absolute recovery was determined.

Extraction with boiling water was carried out with $50.0 \mathrm{mg}$ of powdered plant material, for that $0.3 \mathrm{mg}(100 \%), 0.4 \mathrm{mg}$ (130\%), and $0.7 \mathrm{mg}(150 \%)$ of isoastilbin were added. The repeatability (intraday precision) was determined in triplicate of six points of the calibration curve by the same analyst in the same working day. The accuracy under the repeatability conditions was expressed in relative standard deviation (RSD). The intermediate precision was determined by the same analyst in different days. Three points of the calibration curve were prepared, meaning low, medium, and high concentration in triplicate. The intermediate precision was expressed in RSD. The range of work chosen was between 0.01 (lower limit) and 0.5 $\mathrm{mg} \mathrm{ml} \mathrm{m}^{-1}$ (upper limit) of isoastilbin and as intermediate concentrations $0.03,0.05,0.1$, and $0.3 \mathrm{mg} \mathrm{ml}^{-1}$. The limit of detection (LOD) was determined based on the signal-to-noise ratio (3:1), and the limit of quantification (LOQ) was determined based on the signal-to-noise ratio (10:1). The method was validated; as seen in Supplementary Material, Tables S1-S6. According to the results all values were within acceptable criteria (Borman and Elder, 2018). The LOD and LOQ values were lower than 0.12 and $0.39 \mathrm{mg}$ standard respectively (Supplementary Material, Table S1). Therefore, the method was concluded as suitable to quantify isoastilbin and related phenolic compounds in the plant extract. Over the selected range, peak areas linearly depended on concentrations for all phenolic compounds with high correlation coefficients $(>0.9998$, Table 1). The injection repeatability of the system was evaluated by seven consecutive injections of the standard solution of phenolic compounds. The RSD values of retention times of phenolic compounds were less than $0.60 \%$ (Supplementary Material, Table S6).

\section{Determination of Total Phenolics and Flavonoids Content}

The spectrophotometric quantification of total phenolic content (TPC) and total flavonoid content (TFC) of the lyophilized aqueous extract (infusion) and tincture of the bark of $W$. trichosperma was carried out following the previously reported Folin-Ciocalteu and $\mathrm{AlCl}_{3}$ methodology in a Synergy HTX microplate reader (Biotek, Winoosky, VT, USA) (Kuskoski et al., 2005; Bhaigyabati et al., 2017). Total phenolics using the FolinCiocalteu reagent, the results were derived from a calibration curve of gallic acid $\left(\mathrm{y}=0.0319 \mathrm{x}+0.138, \mathrm{R}^{2}=0.996\right)$. Also, for total flavonoids, the results were derived from the calibration curve of quercetin $\left(\mathrm{y}=0.0136 \mathrm{x}+0.0414, \mathrm{R}^{2}=0.979\right)$. The bark was tested at $1 \mathrm{mg} \mathrm{ml}^{-1}$, Total phenolic content was expressed as milligrams of gallic acid equivalents (GAE) per gram of extracts (mg GAE $\mathrm{g}^{-1}$ extract). Flavonoids were expressed as milligrams of quercetin equivalents (QE) per gram of extracts ( $\mathrm{mg} \mathrm{QE} \mathrm{g}^{-1}$ extract). The determinations were made in triplicate. The values from triplicates are reported as the mean \pm SD. 


\section{In Vitro Antioxidant Activity of W. trichosperma}

The antioxidant activity was evidenced by in vitro assays such as the oxygen radical absorbance capacity (ORAC), bleaching of the free radical 2,2-diphenyl-1-picrylhydracil hydrate (DPPH), Ferric Reducing Antioxidant Power (FRAP) and by the bleaching of 2,2'-azino-bis-(3-ethylbenzothiazoline-6-sulphonic acid (ABTS). These assays were performed for the extracts and the major compound isolated, isoastilbin. Data were recorded in triplicate and expressed as average value.

\section{ABTS Assay}

The ABTS free radical scavenging assay was employed to measure the free radical scavenging activity of extracts of $W$. trichosperma and for isoastilbin. We used the method of Re et al. (1999) with some modifications, a solution of 7 mM ABTS $\left(2,2^{\prime}-\right.$ azino-bis(3-ethylbenzothiazoline-6-sulphonic acid)) and a solution $2.45 \mathrm{mM}$ potassium persulfate in water was prepared. Both aqueous solutions were mixed in a $1: 1$ ratio $(\mathrm{v} / \mathrm{v})$ and incubated for $16 \mathrm{~h}$ in the dark for the formation of the radical at room temperature. After this period, using 96-well plates a volume of $275 \mu \mathrm{l}$ of solution (absorbance 0.7 ) was mixed thoroughly with $25 \mu$ l of standard or the samples, the absorbance was immediately recorded at $734 \mathrm{~nm}$ using a microplate reader. Gallic acid was used as a reference standard (from 1 to $100 \mu \mathrm{g} \mathrm{ml}^{-1}$ ); a curve of extracts of $W$. trichosperma were made (from 19.53 to $625 \mu \mathrm{g} \mathrm{ml}^{-1}$ ) and a curve of isoastilbin (from 19.53 to $2500 \mu \mathrm{g} \mathrm{ml}^{-1}$ ) to calculate their $\mathrm{IC}_{50}$. The percentage of ABTS radical inhibition was calculated according to the following equation:

$$
\text { ABTS inhibition }(\%)=\left(1-\frac{\mathrm{As}-\mathrm{Abs}}{\mathrm{A}: \mathrm{ABTS}}\right) \times 100
$$

As, is the absorbance of the sample with ABTS; Abs, is the absorbance of the mixture of blank and sample; A: ABTS, is the absorbance of the ABTS stock solution. The $\mathrm{IC}_{50}$ was calculated using GraphPad Prism 7 software.

\section{DPPH-Free Radical-Scavenging Activity Assay}

DPPH free radical-scavenging activity was determined according to Brand-Williams et al. (1995) with some modifications. A solution of DPPH $400 \mu \mathrm{M}$ was prepared and using a volume of $150 \mu \mathrm{l}$ of this solution thoroughly mixed with $50 \mu \mathrm{l}$ of standard or the samples, the absorbance was recorded at $515 \mathrm{~nm}$ using a microplate reader and 96-well plates $30 \mathrm{~min}$ later. Gallic acid was used as a reference standard (from 1 to $100 \mu \mathrm{g} \mathrm{ml} \mathrm{m}^{-1}$ ); curves of extracts of $W$. trichosperma (from 19.53 to $625 \mu \mathrm{g} \mathrm{ml}^{-1}$ ) and a curve of isoastilbin (from 19.53 to $2500 \mu \mathrm{g} \mathrm{ml}^{-1}$ ) were prepared. The percentage of DPPH radical inhibition was calculated according to the following equation:

$$
\text { DPPH inhibition } \quad(\%)=\left(1-\frac{\mathrm{As}-\mathrm{Abs}}{\mathrm{A} \mathrm{DPPH}}\right) \times 100
$$

As is the absorbance of the sample with $\mathrm{DPPH}, \mathrm{Abs}$ is the absorbance of the mixture of blank and sample, A DPPH is the absorbance of the DPPH stock solution. The $\mathrm{IC}_{50}$ was calculated using GraphPad Prism 7 software.

\section{Ferric Reducing/Antioxidant Power FRAP Assay}

The method of Collins et al. (1959) with some modifications was used, briefly, a buffer solution $\mathrm{CH}_{3} \mathrm{Na}^{\star} 3 \mathrm{H}_{2} \mathrm{O} 3.1 \% / \mathrm{CH}_{3} \mathrm{COOH}$ (glacial) $16 \%$, dissolved in water plus $20 \mathrm{mM} \mathrm{FeCl}_{3}$ in aqueous solution $\mathrm{HCl} 0.02 \mathrm{M}$ and $10 \mathrm{mM}$ TPTZ dissolved in absolute ethanol. The working solution corresponded to a mixture of one volume of buffer with one volume of $\mathrm{FeCl}_{3}$ and 11 volumes of ethanol. Trolox was used as a reference standard (from 10 to 250 $\mu \mathrm{g} \mathrm{ml} \mathrm{m}^{-1}$ ), for each level of concentration, $290 \mu \mathrm{l}$ of working solution were mixed with $10 \mu \mathrm{l}$ of Trolox in a well of the microplate in triplicate, and then the absorbance was measured at $593 \mathrm{~nm}$ after $5 \mathrm{~min}$, with the data obtained a linear regression equation was used to calculate the concentration of samples.

\section{ORAC Assay}

The assay was carried out on a plate reader, at $37^{\circ} \mathrm{C}$ as reported (Wu et al., 2004). Briefly, AAPH was used as peroxyl generator and Trolox as a standard. Using 48-well microplates, $40 \mu \mathrm{l}$ of sample, blank, and Trolox calibration solutions were mixed in triplicate. The fluorescence of fluorescein disodium (FL) of each cycle was recorded. Parameters for the plate reader were: orbital shaking ( $4 \mathrm{~mm}$ shake width), cycle time, $210 \mathrm{~s}$; position delay, 0.3 s; cycle number, 35; shaking mode, $8 \mathrm{~s}$ before each cycle; injection speed, $420 \mu \mathrm{l} \mathrm{s}^{-1}$. Values were calculated by using a quadratic regression equation between the Trolox or sample concentration and net area under the FL decay curve. Data are expressed as micromoles of Trolox equivalents (TE) per gram of sample $\left(\mu \mathrm{mol}\right.$ of $\left.\mathrm{TE}^{-1}\right)$. The area under curve (AUC) was calculated as

$\mathrm{AUC}=0.5+\mathrm{f} 4 / \mathrm{f} 3+\mathrm{f} 5 / \mathrm{f} 3+\mathrm{f} 6 / \mathrm{f} 3+\cdots+\mathrm{f} 32 / \mathrm{f} 4+\mathrm{f} 33 / \mathrm{f} 4) \times \mathrm{CT}$

where $\mathrm{f} 3=$ fluorescence reading at cycle $3 ; \mathrm{f} n=$ fluorescence reading at cycle $n$; and $\mathrm{CT}$, cycle time in minutes.

\section{Enzyme Inhibitory Activity Cholinesterases (ChE) Inhibition}

The inhibitory activity of these important enzymes was measured thorough the Ellman's method, as stated previously (Mocan et al., 2017). Briefly, DTNB was dissolved in buffer Tris$\mathrm{HCl}$ at $\mathrm{pH} 8.0$ containing $0.1 \mathrm{M} \mathrm{NaCl}$ and $0.02 \mathrm{M} \mathrm{MgCl}_{2}$. Then, a filtered sample solution dissolved in deionized water $(50 \mathrm{ml}$, $2 \mathrm{mg} \mathrm{ml}{ }^{-1}$ ) was mixed with $125 \mathrm{ml}$ of 5-dithio-bis(2nitrobenzoic) acid (DTNB), acetylcholinesterase (AChE), or butyrylcholinesterase (BChE) solution $(25 \mathrm{ml})$ dissolved in Tris- $\mathrm{HCl}$ buffer at $\mathrm{pH} 8.0$ in a 96-well microplate and incubated for $15 \mathrm{~min}$ at $25^{\circ} \mathrm{C}$. Initiation of reaction was performed by the addition of acetyl-thiocholine iodide (ATCI) or butyryl-thiocholine chloride (BTCl) $(25 \mathrm{ml})$. In addition, a blank was prepared by adding the solution sample to all reagents without the enzyme(s) (AChE or BChE) solutions. The sample and blank absorbances were then read at $405 \mathrm{~nm}$ after $10 \mathrm{~min}$ of 
incubation at $25^{\circ} \mathrm{C}$. The absorbance of the sample was subtracted from that of the blank and the cholinesterase inhibitory capacity was expressed as $\mathrm{IC}_{50}\left(\mu \mathrm{g} \mathrm{ml}^{-1}\right.$, concentration range 0.05 to $25 \mu \mathrm{g}$ $\mathrm{ml}^{-1}$ ). Galantamine was used as positive control. All data were collected in triplicate.

\section{Human 5-lipoxygenase (5-hLOX) Inhibition}

The screening inhibitory activity of 5-hLOX was performed fluorescence-based assay is performed using microplates. For this, a 50-mM HEPES buffer was prepared at $\mathrm{pH} 7.5$, which contains $2 \mathrm{mM}$ EDTA, $2 \mathrm{mM} \mathrm{CaCl}_{2}$, and $10 \mu \mathrm{M}$ ATP. A dilution of the human 5-lipoxygenase (5-hLOX) enzyme (1:500) in the reaction buffer was used together with $10 \mu \mathrm{M} 2,7$ dichlorofluorescein diacetate (H2DCFDA dye, fluorimetric probe). The mixture was allowed to incubate in the assay microplate for $15 \mathrm{~min}$ at room temperature. Subsequently, 33.3 $\mu \mathrm{l}$ of the buffer was added to each well of the cell culture plate to be used. To each well, $3.3 \mu \mathrm{l}$ of inhibitor was added and incubated for $30 \mathrm{~min}$. Finally, the reaction was started by the addition of a suitable concentration of arachidonic acid substrate $(3.3 \mu \mathrm{l}, 0.5 \mu \mathrm{M})$, and fluorescence was read in a Synergy ${ }^{\mathrm{TM}} \mathrm{HT}$ Multi-Mode Microplate Reader (Biotek Instruments, Inc, Winooksi, VT, USA) at $480 \mathrm{~nm}$ excitation/520 nm emission after a reaction that had proceeded for $1 \mathrm{~h}$ at room temperature for determine the values of percentage inhibition. Nordihydroguaiaretic acid (NDGA) was used as a positive control. All data were collected in triplicate.

\section{Docking Studies}

The geometries and partial charges of astilbin, isoastilbin, neoastilbin, and neoisoastilbin contained in the $W$. trichosperma aqueous extract, as well as the known cholinesterases (TcAChE- $h \mathrm{BuChE}$ ) inhibitor galantamine and the 5 - $h$ LOX inhibitor zileuton were fully optimized using the DFT method with the standard basis set PBE0/6-311+g* (Adamo and Barone, 1999, Petersson et al., 1988). All calculations were performed in Gaussian 09W software.

\section{Statistical Analysis}

Results were expressed by means of values \pm standard error of nine separate determinations (GraphPad Prism 8). Comparison of means was performed by one-way analysis of variance (ANOVA) ( $\mathrm{p}<0.05$ ) followed by post hoc Tukey honestly significant difference (HSD) test $(\mathrm{p}<0.01)$.

\section{RESULTS AND DISCUSSION}

\section{Centrifugal Partition Chromatography}

The major phenolic compounds present in the extracts, isoastilbin, neoisoastilbin, and neoastilbin $((2 R, 3 S)$ dihydroquercetin 3-O-alpha-L-rhamnoside, $(2 S, 3 R)$ dihydroquercetin 3-O-alpha-L-rhamnoside, $(2 S, 3 S)$ dihydroquercetin 3-O-alpha-L-rhamnoside) were isolated using a countercurrent chromatography (CCC) machine, and a biphasic solvent system HEMWAT 1:9:1:9. The partition coefficient is the parameter that reflects the distribution of the solute between the two mutually balanced solvent phases. The ideal partition coefficient, for optimum CCC performance, must be a $k$ value between 0.4 and 2.5 (Friesen and Pauli, 2005; Kumar, 2015). It is necessary to point out that to obtain an efficient separation and an adequate execution time the value $\mathrm{k}$ should be close to 1.0 (Kumar, 2015). On the one hand, in the event that the partition coefficient is much smaller than 1.0, the loss of the maximum resolution results as the solutes would be close to each other on the solvent front (Kumar, 2015). On the other hand, in the case that the value of $k$ is much greater than 1 , elution of the solutes in excessively wide peaks (band widening) would occur, which can lead to a prolonged elution time (Kumar, 2015). For all the above, the biphasic solvent system 1:9:1:9 (v/v) with a $k$ value equal to $1.55 \pm 009$ was chosen (Table 1). This solvent system allowed to separate in a step the main compound present in the ethanolic extract of $W$. trichosperma.

\section{HPLC-PDA-OT-MS}

In this study, through HPLC-PDA-OT-MS analysis, twenty-five compounds were tentatively identified in the ethanolic extract of W. trichosperma bark (Figure 2). The structures of the compounds were proposed based on UV absorption and MS fragmentation patterns (Table 2). The detailed analysis is explained below.

\section{Phenolic Acids}

Peak 1 was tentatively identified as bergapten (215.03389, $\mathrm{C}_{12} \mathrm{H}_{7} \mathrm{O}_{4}{ }^{-}$), (Acharya et al., 2019) peaks 2 and 3 as the isomers galloylglucose (331.06597, $\mathrm{C}_{15} \mathrm{H}_{13} \mathrm{O}_{6}^{-}$) (Salminen et al., 2014), and galloylgalactose $\left(\mathrm{C}_{15} \mathrm{H}_{13} \mathrm{O}_{6}{ }^{-}\right)$, respectively. Peak 4 with a M$\mathrm{H}^{-}$ion at $m / z$ : 169.01315 as gallic acid $\left(\mathrm{C}_{15} \mathrm{H}_{13} \mathrm{O}_{6}{ }^{-}\right)$, Peak 5 as phlorigidoside $\mathrm{B}$ (463.14462 $\mathrm{C}_{19} \mathrm{H}_{27} \mathrm{O}_{13}{ }^{-}$) (Takeda et al., 2001), and finally peak 6 as verbasoside (461.16535 $\left.\mathrm{C}_{20} \mathrm{H}_{29} \mathrm{O}_{12}{ }^{-}\right)$ (Quirantes-Piné et al., 2009), while peak 24 was identified as pentyl benzoate, (435.09219, $\mathrm{C}_{20} \mathrm{H}_{19} \mathrm{O}_{11}{ }^{-}$).

\section{Procyanidins}

Peak 7 with a pseudomolecular ion at $m / z: 577.13405$ producing a catechol moiety at $m / z: 285.06122$ was identified as procyanidin B2 $\left(\mathrm{C}_{30} \mathrm{H}_{25} \mathrm{O}_{12}{ }^{-}\right)$(Glavnik and Vovk, 2019), while peak 9 as epicatequin (289.07199).

\section{Iridoids}

Peak 8 was identified as tudoside (417.10275, $\left.\mathrm{C}_{17} \mathrm{H}_{22} \mathrm{O}_{12}{ }^{-}\right)$ (Venditti et al., 2015), peak 11 as hedanthroside E. (483.11450, $\mathrm{C}_{21} \mathrm{H}_{23} \mathrm{O}_{13}{ }^{-}$)

\section{Chalcones}

Peak 10 with a $\mathrm{M}-\mathrm{H}$ ion at $m / z: 435.12936\left(\mathrm{C}_{21} \mathrm{H}_{23} \mathrm{O}_{10}{ }^{-}\right)$was identified as phlorizine (Liu et al., 2003)

\section{Flavonoids}

Peak 12 was identified as the flavanonol taxifolin-3-O-glucoside $\left(\mathrm{C}_{21} \mathrm{H}_{21} \mathrm{O}_{12}{ }^{-}\right.$) (Sakushima et al., 2002) and peak 13 as its isomer helicioside A (Jia et al., 2018) and peak 15 as naringenin-7-Opentoside $\left(\mathrm{C}_{20} \mathrm{H}_{19} \mathrm{O}_{11}{ }^{-}\right)$. Peaks 20, 21, and 22 as naringenin-4'- 


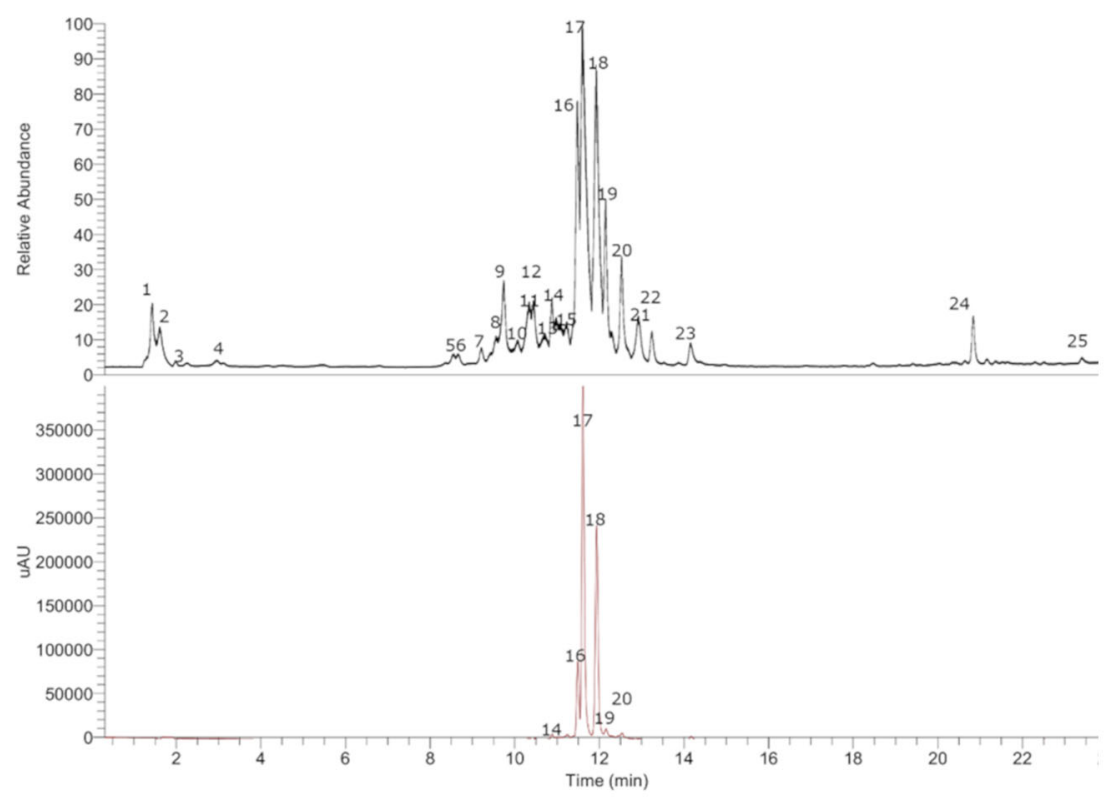

FIGURE 2 | HPLC-ESI-MS/MS profile (black: TIC, red: UV at $280 \mathrm{~nm}$ ) of the infusion of bark from W. trichosperma.

TABLE 2 | Tentative identification of main compounds of $W$. trichosperma by HPLC-PDA-OT-MS.

\begin{tabular}{|c|c|c|c|c|c|c|c|c|}
\hline Peak & $\begin{array}{c}R_{t} \\
(\min )\end{array}$ & $\begin{array}{c}\lambda \max \\
(\mathrm{nm})\end{array}$ & $\begin{array}{c}\text { Elemental } \\
\text { composition } \\
{[\mathrm{M}-\mathrm{H}]^{-}}\end{array}$ & $\begin{array}{l}\text { Theorical } \\
\text { mass }(m / z)\end{array}$ & $\begin{array}{l}\text { Measured } \\
\text { mass }(m / z)\end{array}$ & 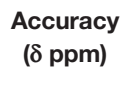 & $\begin{array}{l}\text { Ions MS } \\
\quad(\mathrm{m} / \mathrm{z})\end{array}$ & Tentative identification \\
\hline 1 & 1.42 & & $\mathrm{C}_{12} \mathrm{H}_{7} \mathrm{O}_{4}^{-}$ & 215.03222 & 215.03389 & -7.8 & & Bergapten \\
\hline 2 & 1.62 & & $\mathrm{C}_{15} \mathrm{H}_{13} \mathrm{O}_{6}^{-}$ & 331.06720 & 331.06597 & 3.71 & 125.02363 & Galloylglucose \\
\hline 3 & 2.24 & & $\mathrm{C}_{15} \mathrm{H}_{13} \mathrm{O}_{6}^{-}$ & 331.06689 & 331.06595 & 3.70 & 125.02361 & Galloylgalactose \\
\hline 4 & 2.96 & $198-230-293$ & $\mathrm{C}_{15} \mathrm{H}_{13} \mathrm{O}_{6}^{-}$ & 169.01369 & 169.01315 & 4.58 & 125.02364 & Gallic acid \\
\hline 5 & 8.23 & $198-230-293$ & $\mathrm{C}_{19} \mathrm{H}_{27} \mathrm{O}_{13}^{-}$ & 463.14523 & 463.14462 & 4.58 & 285.04062151 .00308 & Phlorigidoside B \\
\hline 6 & 8.65 & $198-230-293$ & $\mathrm{C}_{20} \mathrm{H}_{29} \mathrm{O}_{12}^{-}$ & 461.16614 & 461.16535 & 4.58 & $\begin{array}{l}285.06122 \\
\text { (catechol) }\end{array}$ & Verbasoside \\
\hline 7 & 9.21 & $198-230-293$ & $\mathrm{C}_{30} \mathrm{H}_{25} \mathrm{O}_{12}^{-}$ & 577.13403 & 577.13405 & 0.35 & $\begin{array}{l}285.06122 \\
\text { (catechol) }\end{array}$ & Procyanidin B2 \\
\hline 8 & 9.53 & $198-230-293$ & $\mathrm{C}_{17} \mathrm{H}_{22} \mathrm{O}_{12}^{-}$ & 417.10358 & 417.10275 & 1.97 & & Tudoside \\
\hline 9 & 9.75 & $198-230-293$ & $\mathrm{C}_{15} \mathrm{H}_{13} \mathrm{O}_{6}^{-}$ & 289.07066 & 289.07199 & 4.58 & & Epicatechin \\
\hline 10 & 10.42 & $198-230-293$ & $\mathrm{C}_{21} \mathrm{H}_{23} \mathrm{O}_{10}^{-}$ & 435.12857 & 435.12936 & 0.76 & & Phlorizin \\
\hline 11 & 10.22 & $198-230-293$ & $\mathrm{C}_{21} \mathrm{H}_{23} \mathrm{O}_{13}^{-}$ & 483.11332 & 483.11450 & 2.64 & 285.04062151 .00308 & Hedanthroside E \\
\hline 12 & 10.46 & 283 & $\mathrm{C}_{21} \mathrm{H}_{21} \mathrm{O}_{12}^{-}$ & 465.10345 & 465.10275 & 1.50 & 269.04437, 161.02782 & Taxifolin-3-O-glucoside \\
\hline 13 & 10.55 & 283 & $\mathrm{C}_{21} \mathrm{H}_{21} \mathrm{O}_{12}^{-}$ & 465.10358 & 465.10275 & 1.77 & $\begin{array}{l}281.10859,339.07106 \\
161.02690\end{array}$ & $\begin{array}{l}\text { Helicioside B } \\
\text { Taxifolin-5-O-glucoside }\end{array}$ \\
\hline 14 & 11.22 & 198-230-293 & $\mathrm{C}_{15} \mathrm{H}_{15} \mathrm{O}_{9}^{-}$ & 339.07216 & 339.07239 & 4.10 & 176.12755 & Esculin \\
\hline 15 & 11.35 & 280 & $\mathrm{C}_{20} \mathrm{H}_{19} \mathrm{O}_{11}^{-}$ & 435.09308 & 435.09219 & 2.04 & $\begin{array}{l}\mathrm{C}_{15} \mathrm{H}_{9} \mathrm{O}_{6}^{-} \\
\text {(naringenin) }\end{array}$ & Naringenin-3-O-pentoside \\
\hline 16 & 11.46 & $198-230-293$ & $\mathrm{C}_{21} \mathrm{H}_{21} \mathrm{O}_{11}^{-}$ & 449.10894 & 449.10922 & 3.08 & 285.04062151 .00308 & Neoastilbin \\
\hline 17 & 11.61 & 198-230-293 & $\mathrm{C}_{21} \mathrm{H}_{21} \mathrm{O}_{11}^{-}$ & 449.10784 & 449.10907 & 2.74 & 285.04062151 .00308 & Isoastilbin \\
\hline 18 & 12.02 & $198-227-290$ & $\mathrm{C}_{21} \mathrm{H}_{21} \mathrm{O}_{11}^{-}$ & 449.10784 & 449.10870 & -3.09 & - & Neoisoastilbin \\
\hline 19 & 12.23 & 198-230-293 & $\mathrm{C}_{21} \mathrm{H}_{21} \mathrm{O}_{11}^{-}$ & 449.10784 & 449.10901 & 2.60 & 285.04062151 .00308 & Astilbin \\
\hline 20 & 12.16 & 203 & $\mathrm{C}_{28} \mathrm{H}_{25} \mathrm{O}_{15}^{-}$ & 433.11560 & 433.11429 & -3.15 & 269.04995, 285.04055152 .01096 & Naringenin-4'-O-glucoside \\
\hline 21 & 12.52 & 286 & $\mathrm{C}_{28} \mathrm{H}_{25} \mathrm{O}_{15}^{-}$ & 601.11880 & 601.11651 & 1.18 & 285.03967 & $\begin{array}{l}\text { Eriodictyol 7-(6'- } \\
\text { galloylglucoside) }\end{array}$ \\
\hline 22 & 12.92 & 288 & $\mathrm{C}_{28} \mathrm{H}_{25} \mathrm{O}_{15}^{-}$ & 433.11560 & 433.11374 & -3.15 & 271.06120152 .01096 & Naringenin-7-O-galactoside \\
\hline 23 & 14.16 & $266-293$ & $\mathrm{C}_{15} \mathrm{H}_{10} \mathrm{O}_{6}^{-}$ & 285.04028 & 285.03936 & 3.22 & - & Kaempferol \\
\hline 24 & 20.84 & 283 & $\mathrm{C}_{12} \mathrm{H}_{15} \mathrm{O}_{2}^{-}$ & 191.10732 & 191.10666 & 3.44 & - & Pentyl benzoate \\
\hline 25 & 23.40 & 283 & $\mathrm{C}_{15} \mathrm{H}_{22} \mathrm{O}_{2}^{-}$ & 233.15436 & 233.15361 & 3.35 & - & Polygodial \\
\hline
\end{tabular}


$O$-glucoside, eriodictyol 7-(6'"-galloylglucoside) $\left(\mathrm{C}_{28} \mathrm{H}_{25} \mathrm{O}_{15}{ }^{-}\right)$ and naringenin-7-O-glucoside (prunin, $\mathrm{C}_{28} \mathrm{H}_{25} \mathrm{O}_{15}{ }^{-}$) (Ali et al., 2019), respectively. Finally, Peak 24 was identified as kaempferol $\left(\mathrm{C}_{15} \mathrm{H}_{10} \mathrm{O}_{6}^{-}\right)$.

\section{Flavanones}

Peaks 16 to 19 were identified as neoastilbin, isoastilbin, neoisoastilbin, and astilbin (Figure 3). $\left(\mathrm{C}_{21} \mathrm{H}_{21} \mathrm{O}_{11}{ }^{-}\right.$) (Zhang et al., 2013), respectively, using spiking experiments with standard compounds. The structural identification of isoastilbin was confirmed by NMR analysis (Supplementary Material, Figures S3-S9).

\section{Coumarins}

Peak 14 was identified as esculin $\left(339.07239, \mathrm{C}_{15} \mathrm{H}_{15} \mathrm{O}_{9}{ }^{-}\right.$) (Qazi et al., 2018)

\section{Sesquiterpenes}

Peak 25 was regarded as polygodial (Barrosa et al., 2016).

\section{HPLC-PDA Quantitation}

Isomers of astilbin were quantified by HPLC-PDA and the methodology validated; (as seen in Supplementary Material, Tables S1-S6), the method was suitable to quantify isoastilbin and related phenolic compounds in the bark extract. In the infusion, four isomers were found but only three mayor isolated ones quantified, the highest amount found was for isoastilbin, followed by neoisoastilbin, and neoastilbin (141.7366 \pm 1.18 , $99.59 \pm 0.83$, and $53.1795 \pm 0.31 \mathrm{mg} / \mathrm{g}$ extract, respectively), this makes the bark a good source for those bioactive isomer glycoside compounds.

\section{Total Phenolic Content, Total Flavonoid Content, and Antioxidant Activity}

Total phenolic content (TPC) and total flavonoid content (TFC) was measured of the aqueous extract of $W$. trichosperma to determine if the antioxidant activity was directly related to the content of these metabolites. The content of phenolic compounds in aqueous extracts of $W$. trichosperma was 442.1 $\pm 21.1 \mathrm{mg} \mathrm{GAE} \mathrm{g}^{-1}$ dry plant (Table 3). The flavonoid content in aqueous extract was $1.554 \pm 0.111 \mu \mathrm{g}$ of quercetin equivalents per gram of dry plant. On the other hand, we used the $\mathrm{ABTS}^{\circ+}$ and $\mathrm{DPPH}$ assays to perform the assessment of the bleaching capacities of the aqueous extract of $W$. trichosperma and the major compound isolated, isoastilbin, the two assays showed a concentration-dependent increases in radical scavenging activity both the extract and isoastilbin, and we compared the data with the $\mathrm{IC}_{50}$ value of standard gallic acid for each method, as presented in Table 3, for ABTS assay the $\mathrm{IC}_{50}$ value for gallic acid was $0.09855 \pm 0.00026 \mu \mathrm{g}$ of gallic acid per milliliter and for $\mathrm{DPPH}$ assay was $0.4622 \pm 0.0015 \mu \mathrm{g}$ of gallic acid per milliliter. Also, for FRAP assay, the results were derived from a calibration

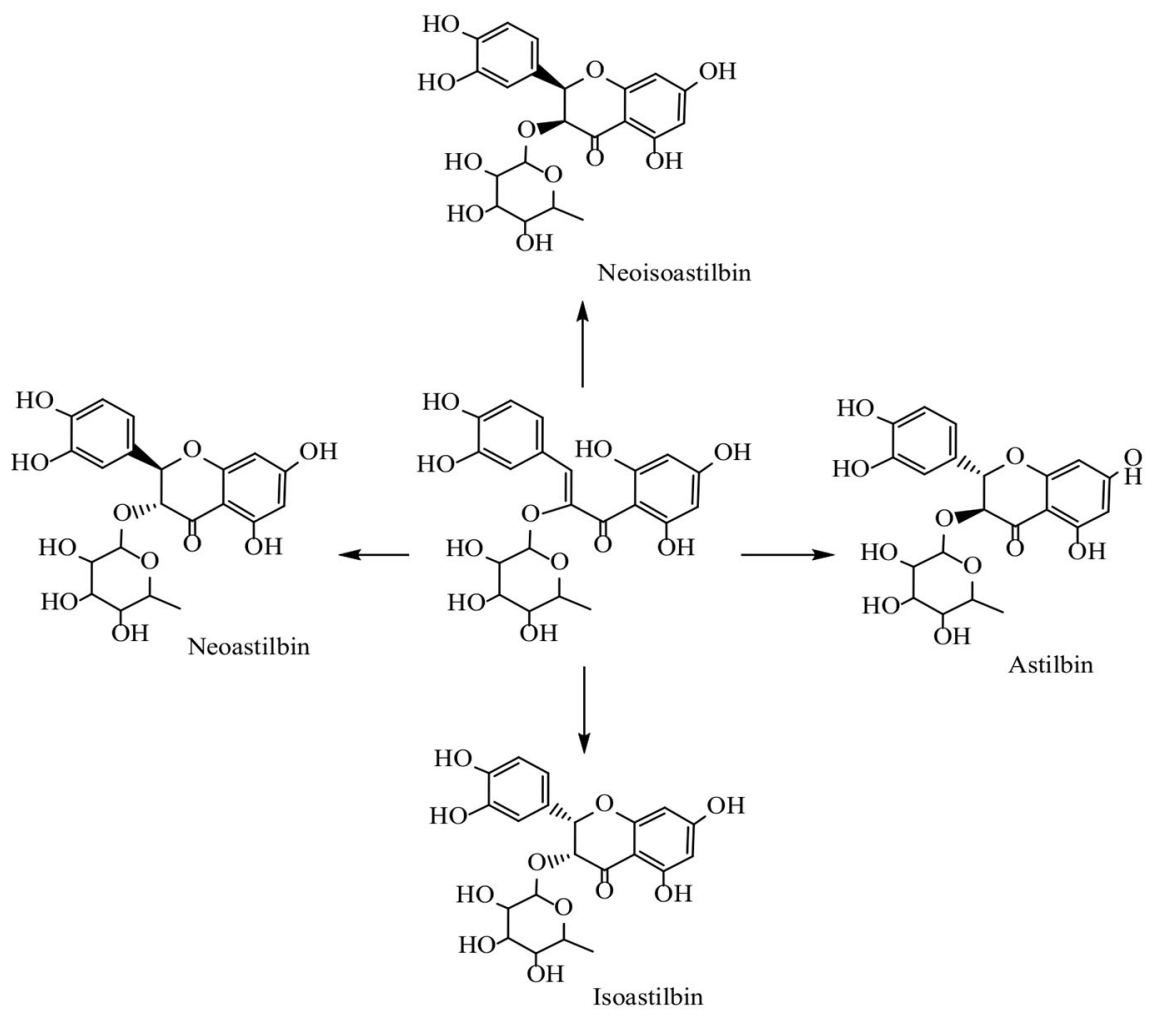

FIGURE 3 | Biosynthetic relationship of the isomers of isoastilbin detected in the bark of $W$. trichosperma. 
TABLE 3 | Total phenolics, flavonoids, antioxidant, and inhibition of cholinesterase and 5-hLOX for infusion and tincture of W. trichosperma and the main isolated compound, isoastilbin.

\begin{tabular}{|c|c|c|c|c|c|}
\hline Assay & Infusion of W. trichosperma & $\begin{array}{l}\text { Tincture of } W . \\
\text { trichosperma }\end{array}$ & Gallic acid & Isoastilbin & Galantamine/NDGA \\
\hline TPC & $442.1 \pm 21.1^{\mathrm{a}}$ & $438.3 \pm 22.2^{\mathrm{a}}$ & - & - & - \\
\hline TFC & $15.54 \pm 0.11^{b}$ & $15.45 \pm 0.11^{b}$ & - & - & - \\
\hline DPPH IC ${ }_{50}$ & $20.58 \pm 2.46^{c}$ & $20.33 \pm 2.18^{c}$ & $0.4622 \pm 0.0015^{k}$ & $33.1 \pm 2.1^{d}$ & - \\
\hline ABTS IC 50 & $3.070 \pm 0.095^{c}$ & $3.055 \pm 0.082^{c}$ & $0.0985 \pm 0.0003^{k}$ & $2.525 \pm 0.261^{d}$ & - \\
\hline FRAP & $2.700 \pm 0.554^{\mathrm{e}}$ & $2.650 \pm 0.532^{\mathrm{e}}$ & - & $0.149 \pm 0.016^{f}$ & - \\
\hline ORAC & $1270 \pm 36.5^{9}$ & $1248 \pm 32.3^{9}$ & - & $1901 \pm 33.5^{\mathrm{g}}$ & - \\
\hline Acetylcholinesterase inhibition IC $_{50}$ & $\begin{array}{l}3.13 \pm 0.03^{h} \\
\left(33.80 \% \text { at } 1 \mu \mathrm{g} \mathrm{ml}^{-1}\right)\end{array}$ & $\begin{array}{l}3.08 \pm 0.02^{\mathrm{h}} \\
\left(33.50 \% \text { at } 1 \mu \mathrm{g} \mathrm{ml}^{-1}\right)\end{array}$ & - & $\begin{array}{l}4.68 \pm 0.03^{h} \\
(51.70 \% \text { at } 2.2 \mu \mathrm{M})\end{array}$ & $\begin{array}{l}0.26 \pm 0.02^{h} \\
(69.42 \% \text { at } 3.48 \mu \mathrm{M})\end{array}$ \\
\hline Butirylcholinesterase inhibition $\mathbf{I C}_{50}$ & $\begin{array}{l}2.94 \pm 0.08^{\mathrm{h}} \\
\left(33.12 \% \text { at } 1 \mu \mathrm{g} \mathrm{ml}^{-1}\right)\end{array}$ & $\begin{array}{l}2.76 \pm 0.08^{\mathrm{h}} \\
\left(33.12 \% \text { at } 1 \mu \mathrm{g} \mathrm{ml}^{-1}\right)\end{array}$ & - & $\begin{array}{l}8.51 \pm 0.03^{h} \\
(50.10 \% \text { at } 2.2 \mu \mathrm{M})\end{array}$ & $3.82 \pm 0.02^{h}$ \\
\hline $\begin{array}{l}\text { 5-hLOX inhibition } \\
\text { (\%) }\end{array}$ & $\begin{array}{l}82.86 \pm 4.31 \\
\left(\text { at } 0.05 \mu \mathrm{g} \mathrm{ml}^{-1}\right)^{\mathrm{i}}\end{array}$ & - & - & $\begin{array}{l}34.29 \pm 3.11 \\
(\text { at } 10 \mu \mathrm{M})^{i} \\
80.71 \pm 7.29 \\
\text { (at } 40 \mu \mathrm{M})^{i}\end{array}$ & $\begin{array}{l}93.50 \\
\pm 4.2(\text { at } 10 \mu \mathrm{M})^{\mathrm{i}}\end{array}$ \\
\hline
\end{tabular}

All values were expressed as means $\pm S D(n=3)$.

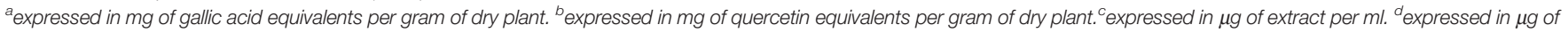
isoastilbin per milliliter. ${ }^{e}$ expressed in mmol Trolox equivalent per gram of dry plant. ${ }^{f}$ expressed in mmol trolox equivalent per mg of isoastillbin. ${ }^{k}$ expressed in $\mu \mathrm{g}$ of gallic acid per ml. ${ }^{g}$ expressed in $\mu \mathrm{M}$ Trolox equivalents per 100 grams of dry plant. ${ }^{h} / \mathrm{C}_{50}$ in $\mu \mathrm{g}$ per $\mathrm{ml} .{ }^{i}$ Concentration Stock Solution equal to $1.52 \mathrm{mg}$ per $\mathrm{ml}^{-1}$.

curve of Trolox $\left(y=0.0019 x+0.0178, R^{2}=0.997\right)$, for the aqueous extract this was $2.700 \pm 0.554 \mathrm{mmol}$ Trolox equivalent per gram of dry plant and for isoastilbin this was $0.1494 \pm 0.0166$ mmol Trolox equivalent per milligram of isoastilbin. For ORAC assay, the results support the hypothesis that the antioxidant activity is related with the content of the phenolic compounds present in the extract of the bark of W. trichosperma.

\section{In Vitro 5-hLOX and Cholinesterase Inhibitory Enzyme Assay}

The application of enzyme inhibition therapeutic approaches is considered effective to control several health degenerative diseases, including Alzheimer's disease, arthritis, and arthrosis. LOXs are a class of enzymes that catalyze the oxygenation of poly-unsaturated fatty acids in cis,cis-1,4-pentadiene structures, which are classified in order to their arachidonic acid oxidation specificity as 5, 8, 12, and 15-LOX. Indeed, the enzymes cyclooxygenase (COX), lipoxygenase (LOX), and matrix Metalloproteinase (MMP) are closely related to inflammatory responses, key factors in joint and arterial health. They are important key factors in immunity responses and pathological processes, such as wound healing, arthrosis, rheumatoid arthritis, pain, cancer, fever, and inflammatory reactions. On the other hand, the first therapeutic line for the treatment of degenerative Alzheimer's disease are cholinesterase inhibitors (Howes et al., 2003). In this study, an in vitro inhibitory effect of the aqueous extract of $W$. trichosperma, on 5-hLOX, acetylcholinesterase, and butyrilcholinesterase enzymes was investigated.

The aqueous extract of $W$. trichosperma showed an interesting activity as 5-hLOX inhibitor of $82.86 \%$ (at $0.05 \mu \mathrm{g}$ $\mathrm{ml}^{-1}$ ), while isolated isoastilbin was $34.29 \%$ (at $10 \mu \mathrm{M}$ ) and $80.71 \%$ (at $40 \mu \mathrm{M}$ ) (Table 3). Within the identified compounds, neoastilbin, isoastilbin, neoisoastilbin, and astilbin have shown anti-inflammatory activity through a mechanism that related to lipopolysaccharide-stimulated PGE(2) release, and Tumour
Necrosis Factor alpha (TNF- $\alpha$ ) and nitric oxide (NO) production from RAW 264.7 cells (Qureshi et al., 2011). In addition, Bergapten exhibited significant inhibition of the production of pro-inflammatory cytokines, namely, TNF- $\alpha$ and interleukin-6 (IL-6) by human peripheral blood mononuclear cells (PBMCs) stimulated with lipopolysaccharide in a concentration-dependent manner (Bose et al., 2011), and also exhibit an anti-inflammatory activity by inhibiting reactive oxygen species (ROS) and NO accumulation in the tail-cuttinginduced inflammation zebrafish model (Yang et al., 2018b). Gallic acid suppresses the activation of nuclear factor kappalight-chain-enhancer of activated B cells (NF- $k \mathrm{~B}$ ), COX-1, COX2, p65 acetylation, Histone acetyltransferases (HAT), Intercellular adhesion molecule-1 (ICAM-1), Vascular cell adhesion molecule 1 (VCAM-1), TNF- $\alpha$, interleukin- $1 \beta$ (IL$1 \beta)$, IL-6, and inducible nitric oxide synthase (iNOS) (Kroes et al., 1992; Locatelli et al., 2013). Procyanidin B2 exerts antiinflammatory activity and molecular mechanisms targeted include the modulation of various mediators of inflammation, including eicosanoids, cytokines, and NO, NLR Family Pyrin Domain Containing 3 (NLRP3) inflammasome, as well as the $\mathrm{NF}-\kappa \mathrm{B}$ and mitogen-activated protein kinase (MAPK) pathways (Martinez-Micaelo et al., 2012; Jiang et al., 2018). Epicatechin effectively attenuates the production of inflammatory mediators including NO, PGE2, TNF- $\alpha$, IL-1 $\beta$, and IL- 6 in the LPSinduced macrophages through inactivation of NF- $\kappa \mathrm{B}$, MAPKs (ERK, JNK, and p38) and JAK2/STAT3 pathways (Yang et al., 2015). Esculin has potent anti-inflammatory activities in vivo and in vitro, which may involve the inhibition of the MAPK pathway (Niu et al., 2015). Kaempferol showed potent effect in the inhibition of inflammatory cell function as well as inhibition in the expression of pro-inflammatory cytokines and chemokines (Devi et al., 2015). Polygodial inhibited significantly the mouse paw edema induced by prostaglandin E2, bradykinin (BK), substance $\mathrm{P}(\mathrm{SP})$, dextran, platelet activating factor (PAF) or 
carrageenan, and also inhibited arachidonic acid-, capsaicin- and croton oil-induced ear edema in mice (da Cunha et al., 2001). Flavanones were regarded previously as anti-inflammatory showing inhibitory effects on lipopolysaccharide-stimulated PGE(2) release, and TNF- $\alpha$ and NO production from RAW 264.7 cells (Qureshi et al., 2011).

The inhibition of both the AChE and BChE cholinesterase enzymes is believed to be beneficial over inhibiting only one of the enzymes. The results of $W$. trichosperma inhibitory potencies of choline esterase (AChE and BChE) inhibitory activities are shown in Table 3 and expressed as $\mathrm{IC}_{50}$, particularly, AChE inhibition $\mathrm{IC}_{50}$ was $3.13 \pm 0.03 \mu \mathrm{g} \mathrm{ml}^{-1}\left(33.8 \%\right.$ at $\left.1 \mu \mathrm{g} \mathrm{ml}{ }^{-1}\right)$ and BChE inhibition $\mathrm{IC}_{50}$ was $2.94 \pm 0.08 \mu \mathrm{g} \mathrm{ml}^{-1}(33.12 \%$ at $1 \mu \mathrm{g}$ $\mathrm{ml}^{-1}$ ) while its component isomer isoastilbin its $\mathrm{IC}_{50}$ was $4.68 \pm$ $0.03 \mu \mathrm{g} \mathrm{ml}^{-1}(51.70 \%$ at $2.2 \mu \mathrm{M})$ and $8.51 \pm 0.03 \mu \mathrm{g} \mathrm{ml}^{-1}(50.10 \%$ at $2.2 \mu \mathrm{M})$ for AChE and BChE, respectively.

\section{Docking Studies}

The isomers astilbin, isoastilbin, neoastilbin, and neoisoastilbin (Supplementary Material, Figure S10) contained in $W$. trichosperma as well as the known inhibitors of acetylcholinesterase (TcAChE), butyrylcholinesterase ( $h \mathrm{BuChE})$ and 5-lipoxygenase (5-hLOX), galantamine, and zileuton, were subjected to docking assays into their catalytic sites. The best docking binding energies expressed in $\mathrm{kcal} / \mathrm{mol}$ of each compound are shown in Table 4. By the analysis of docking poses in this enzyme, astilbin and isoastilbin are arranged in similar manners with a slightly tilt between their molecular structures. Indeed, the 5,7-dihydroxychroman-4-one, dihydroxyphenyl, and glycoside portions are quite overlapped, which could explain the similarities in their binding energy values $(-8.92$ and -8.59 $\mathrm{kcal} \mathrm{mol}^{-1}$, respectively). The relative superposition between astilbin and isoastilbin mentioned above results in that both isomers interacts with some same amino acids of the acetylcholinesterase catalytic site (Supplementary Material, Figures S11A, B). In this sense, the hydroxyl groups $(-\mathrm{OH})$ at position 7- of the 5,7-dihydroxychroman-4-one frameworks, one of the hydroxyl groups $(-\mathrm{OH})$ of the glycosides moieties and one of the hydroxyl groups $(-\mathrm{OH})$ of the dihydroxyphenyl cores of both astilbin and isoastilbin molecules showed hydrogen bond interactions with the amino acids Glu199, Tyr121, and Asn85, respectively. The only difference between the aforementioned interactions of these two molecules is specifically in the
Hydrogen bond interaction performed by the hydroxyl group $(-\mathrm{OH})$ of the glycoside core in astilbin, which take place between the oxygen atom of the saccharide and the hydrogen atom of Tyr121, whereas in isoastilbin occurs exactly the opposite. Figure 4 shows the Hydrogen bond interactions in a two-dimensional diagram of isoastilbin binding mode into every catalytic site of the three studied enzymes as a pure and sole inhibitor in experimental inhibition assays. Binding energy data of flavonoids astilbin, isoastilbin, and neoastilbin obtained from docking assays over acetylcholinesterase shown in Table 4, exhibited similar values. This suggest that all these isomers possess similar ability to inhibit this enzyme. The similar binding energy values of these three compounds could explain why the experimental $\mathrm{IC}_{50}$ of the $W$. trichosperma aqueous extract and the $\mathrm{IC}_{50}$ of the isolated isoastilbin showed such close values $\left(4.68 \pm 0.03\right.$ and $3.13 \pm 0.32 \mu \mathrm{g} \mathrm{ml}^{-1}$, respectively). On the other hand, neoisoastilbin presented the best binding energy profile, which could lead to a higher inhibitory potency if this compound were isolated and tested as a single inhibitor. Therefore, since the $W$. trichosperma aqueous extract contain the four isomers (astilbin, isoastilbin, neoastilbin, and neoisoastilbin) the eventual higher potency of neoisoastilbin compared to the other three isomers, it cannot be detected due the existing competition among all flavonoids for the acetylcholinesterase catalytic site.

\section{CONCLUSIONS}

This study deals with the antioxidant, and enzyme inhibitory effects of Weinmannia trichosperma, in order to find new endemic and underutilized sources of natural products for potential applications in human health. This study makes new contributions to the chemistry of this plant, not previously described. The CPC machine was useful for the isolation of the major compounds while the HPLC-MS allowed the identification of several phenolic constituents. In this study, the assessment of antioxidant activity indicates that the bark could be an important source of natural antioxidants and inhibitory compounds for potential use in neurodegenerative diseases. Hence, $W$. trichosperma bark could be recommended for the formulation of nutraceuticals or antioxidant-rich therapeutic diets and for its enzyme inhibitory properties it can have potential applications in

TABLE 4 | Binding energies obtained from docking experiments of astilbin, isoastilbin, neoastilbin, neoisoastilbin, and the respective known enzyme inhibitors galantamine and zileuton over acetylcholinesterase (TCAChE) (Supplementary Material, Figure S11), butyrylcholinesterase ( $h B$ BuChE) (Supplementary Material, Figure S12) and 5-lipoxygenase (5- $h$ LOX) (Supplementary Material, Figure S13).

\begin{tabular}{|c|c|c|c|}
\hline Compound & $\begin{array}{c}\text { Binding energy (kcal/mol) } \\
\text { Acetylcholinesterase (TcAChE) }\end{array}$ & $\begin{array}{l}\text { Binding energy (kcal/mol) } \\
\text { Butyrylcholinesterase ( } h \text { BuChE) }\end{array}$ & $\begin{array}{l}\text { Binding energy (kcal/mol) } \\
\text { 5-lipoxygenase (5- hLOX) }\end{array}$ \\
\hline Astilbin & -8.92 & -9.41 & -3.61 \\
\hline Isoastilbin & -8.59 & -9.25 & -1.17 \\
\hline Neoastilbin & -9.78 & -9.38 & -1.3 \\
\hline Neoisoastilbin & -10.37 & -8.98 & 2.33 \\
\hline Galantamine & -11.81 & -9.5 & - \\
\hline Zileuton & - & - & -7.25 \\
\hline
\end{tabular}




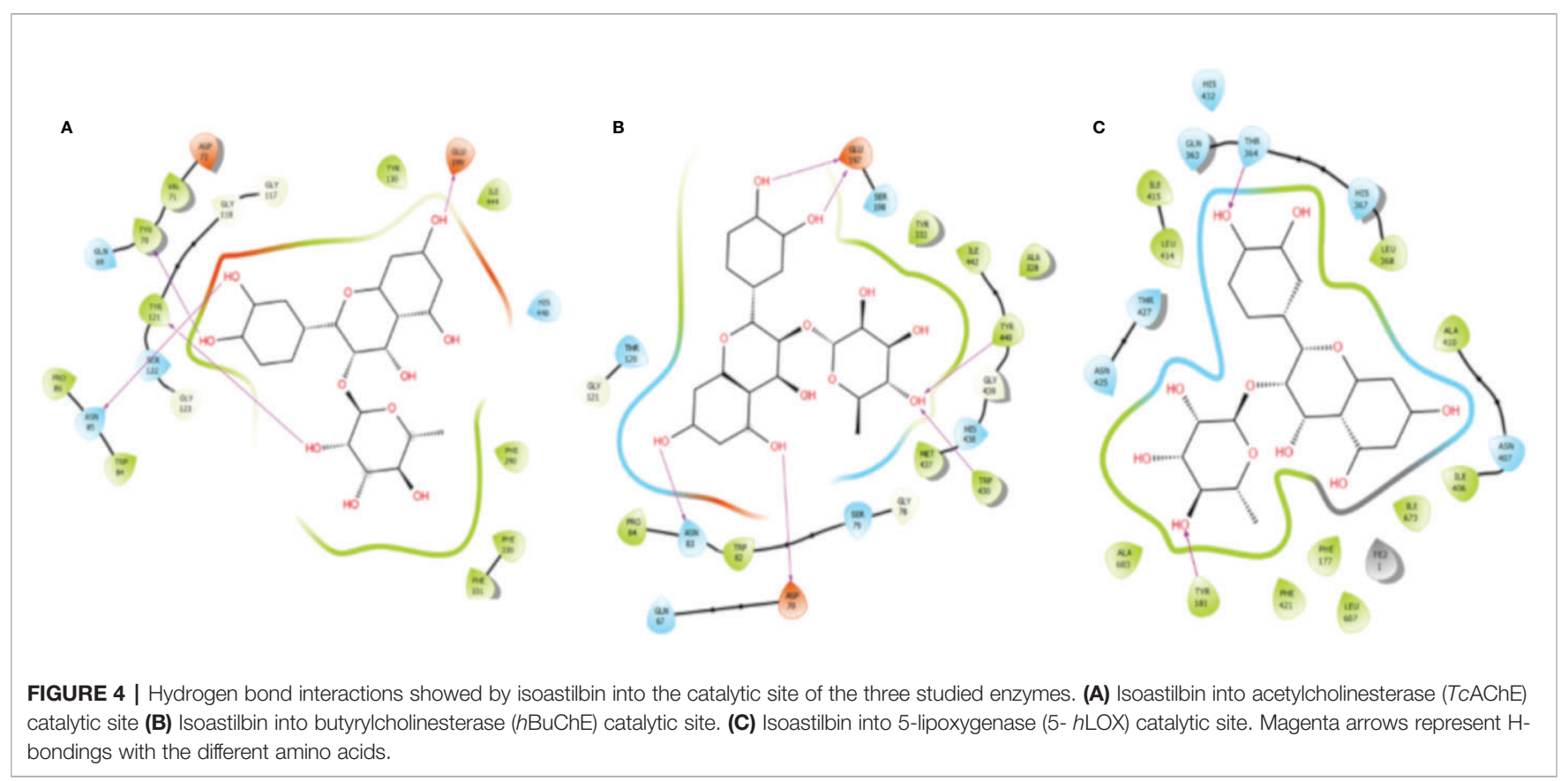

drug industry for the develop of treatment for Alzheimer's disease, as well as to alleviate inflammatory processes involved in other pathologies and diseases. However, more detailed in vivo studies are needed to evaluate the safety and efficacy of the bark.

\section{DATA AVAILABILITY STATEMENT}

All datasets generated for this study are included in the article/ Supplementary Material.

\section{AUTHOR CONTRIBUTIONS}

$\mathrm{RB}$ and EP performed isolation by CPC. MS and CF-G performed LC-MS experiments and analysis. RB and SA performed quantitation by HPLC-PDA. JE performed the NMR analysis. SA and CF-G performed the enzymatic experiments and analysis. JR-P performed the docking studies. MS, JE, and EP wrote the manuscript.

\section{REFERENCES}

Acharya, R., Chacko, S., Bose, P., Lapenna, A., and Pattanayak, S. P. (2019). Structure Based Multitargeted Molecular Docking Analysis of Selected Furanocoumarins against Breast Cancer. Sci. Rep. 9, 15743. doi: 10.1038/ s41598-019-52162-0

Adamo, C., and Barone, V. (1999). Toward reliable density functional methods without adjustable parameters: The PBE0 model Seeking for parameter-free double-hybrid functionals: The PBE0-DH model Accurate excitation energies from time-dependent density functional theory: Assessing the PBE0 model Toward reliable density functional methods without adjustable parameters: The PBE0 model. Cit. J. Chem. Phys. 110, 2889. doi: 10.1063/1.478522

\section{FUNDING}

This research received funds from FONDECYT regular 1180059, Postdoctorado grants 3190794, and 3190572, and doctorado grant CONICYT PFCHA/beca doctorado nacional/201921191978. JE gratefully acknowledges funding from CONICYT (PAI/ACADEMIA N 79160109).

\section{ACKNOWLEDGMENTS}

We acknowledge Milena Rios for her help in in vitro microplate assays.

\section{SUPPLEMENTARY MATERIAL}

The Supplementary Material for this article can be found online at: https://www.frontiersin.org/articles/10.3389/fphar.2020. 00780/full\#supplementary-material

Ali, M. Y., Jannat, S., Edraki, N., Das, S., Chang, W. K., Kim, H. C., et al. (2019). Flavanone glycosides inhibit $\beta$-site amyloid precursor protein cleaving enzyme 1 and cholinesterase and reduce $A \beta$ aggregation in the amyloidogenic pathway. Chem. Biol. Interact. 309, 108707. doi: 10.1016/j.cbi.2019.06.020

Barrosa, K. H., Mecchi, M. C., Rando, D. G., Ferreira, A. J. S., Sartorelli, P., Valle, M. M. R., et al. (2016). Polygodial, a sesquiterpene isolated from Drimys brasiliensis (Winteraceae), triggers glucocorticoid-like effects on pancreatic $\beta$ cells. Chem. Biol. Interact. 258, 245-256. doi: 10.1016/j.cbi.2016.09.013

Bhaigyabati, T., Devi, P. G., Devi, N. R., and Bag, G. C. (2017). Antioxidant activity, total phenolic and total flavonoid content of Oenanthe javanica Blume (DC) collected from Imphal West District. Int. Reseach J. Pharm. 8, 63-68. doi: $10.7897 / 2230-8407.08698$ 
Borman, P., and Elder, D. (2018). "Q2(R1) Validation of Analytical Procedures: Text and Methodology," in ICH Quality Guidelines: An Implementation Guide. Eds. A. Teasdale, D. Elder and R. Nims, John Wiley \& Sons, Inc. 127-166.

Bose, S. K., Dewanjee, S., Sahu, R., and Dey, S. P. (2011). Effect of bergapten from Heracleum nepalense root on production of proinflammatory cytokines. Nat. Prod. Res. 25, 1444-1449. doi: 10.1080/14786410902800665

Brand-Williams, W., Cuvelier, M. E., and Berset, C. (1995). Use of a free radical method to evaluate antioxidant activity. LWT - Food Sci. Technol. 28, 25-30. doi: 10.1016/S0023-6438(95)80008-5

Collins, P., Diehl, H., and Smith, F. (1959). 2,4,6-Tripyridyl-s-triazine as a Reagent for Iron Determination of Iron in Limestone, Silicates, and Refractories. Anal. Chem. 31, 1862-1867. doi: 10.1021/ac60155a056

da Cunha, F. M., Fröde, T. S., Mendes, G. L., Malheiros, A., Cechinel Filho, V., Yunes, R. A., et al. (2001). Additional evidence for the anti-inflammatory and anti-allergic properties of the sesquiterpene polygodial. Life Sci. 70, 159-169. doi: 10.1016/S0024-3205(01)01387-X

Deng, H., Wang, H., Liang, M., and Su, X. (2019). A novel approach based on supramolecular solvent microextraction and UPLC-Q-Orbitrap HRMS for simultaneous analysis of perfluorinated compounds and fluorine-containing pesticides in drinking and environmental water. Microchem. J. 151, 104250. doi: $10.1016 /$ j.microc.2019.104250

Devi, K. P., Malar, D. S., Nabavi, S. F., Sureda, A., Xiao, J., Nabavi, S. M., et al. (2015). Kaempferol and inflammation: From chemistry to medicine. Pharmacol. Res. 99, 1-10. doi: 10.1016/j.phrs.2015.05.002

Friesen, J. B., and Pauli, G. F. (2005). G.U.E.S.S. - A generally useful estimate of solvent systems in CCC. J. Liq. Chromatogr. Relat. Technol. 28, 2777-2806. doi: 10.1080/10826070500225234

Friesen, J. B., McAlpine, J. B., Chen, S. N., and Pauli, G. F. (2015). Countercurrent Separation of Natural Products: An Update. J. Nat. Prod. 78, 1765-1796. doi: $10.1021 / \mathrm{np} 501065 \mathrm{~h}$

Glavnik, V., and Vovk, I. (2019). High performance thin-layer chromatographymass spectrometry methods on diol stationary phase for the analyses of flavan3 -ols and proanthocyanidins in invasive Japanese knotweed. J. Chromatogr. A 1598, 196-208. doi: 10.1016/j.chroma.2019.03.050

Gusinde, M. (1936). Plantas medicinales que los indios Araucanos recomiendan.(Fin). Anthropos, 850-873.

Holler, J. G., Søndergaard, K., Slotved, H.-C., Gúzman, A., and Mølgaard, P. (2012). Evaluation of the antibacterial activity of Chilean plants traditionally used for wound healing therapy against multidrug-resistant Staphylococcus aureus. Planta Med. 78, 200-205. doi: 10.1055/s-0031-1280316

Houghton, P., and Manby, J. (1985). Medicinal plants of the mapuche. J. Ethnopharmacol. 13, 89-103. doi: 10.1016/0378-8741(85)90063-7

Howes, M.-J. R., Perry, N. S. L., and Houghton, P. J. (2003). Plants with traditional uses and activities, relevant to the management of Alzheimer's disease and other cognitive disorders. Phyther. Res. 17, 1-18. doi: 10.1002/ptr.1280

Ito, Y. (2005). Golden rules and pitfalls in selecting optimum conditions for highspeed counter-current chromatography. J. Chromatogr. A. (2), 145-168. doi: 10.1016/j.chroma.2004.12.044

Jia, X., Xie, H., Jiang, Y., and Wei, X. (2018). Flavonoids isolated from the fresh sweet fruit of Averrhoa carambola, commonly known as star fruit. Phytochemistry 153, 156-162. doi: 10.1016/j.phytochem.2018.06.007

Jiang, Y., Yang, W., and Gui, S. (2018). Procyanidin B2 protects rats from paraquat-induced acute lung injury by inhibiting NLRP3 inflammasome activation. Immunobiology 223, 555-561. doi: 10.1016/j.imbio.2018.07.001

Kowalska, T., Sherma, J., and Waksmundzka-Hajnos, M. (2007). "“'Overview of the Field of TLC in Phytochemistry and the Structure of the Book,", " in Thin Layer Chromatography in Phytochemistry. Eds. M. Wkamundzka-Hajnos, J. Sherma and T. Kowalska (Boca Raton, FL:CRC Press), 3-14. doi: 10.1201/ 9781420046786.pt1

Kroes, B. H., Van den Berg, A. J. J., Van Ufford, H. C. Q., Van Dijk, H., and Labadie, R. P. (1992). Anti-inflammatory activity of gallic acid. Planta Med. 58, 499-504. doi: 10.1055/s-2006-961535

Kumar, S. (2015). Analytical Techniques for Natural Product Research. Ed. D. Nicki (Boston, MA: CABI).

Kuskoski, E. M., Asuero, A. G., Troncoso, A. M., Mancini-Filho, J., and Fett, R. (2005). Aplicación de diversos métodos químicos para determinar actividad antioxidante en pulpa de frutos. Ciência e Tecnol. Aliment. 25 (4), 726-732. doi: 10.1590/S0101-20612005000400016
Liu, H., Qu, G., and Yao, X. (2003). The polyphenolic constituents of Engelhardtia serrata stem bark. Pharm. Biol. 41, 305-307. doi: 10.1076/phbi.41.4.305.15675

Liu, Y., Friesen, J., McAlpine, J., and Pauli, G. (2015). Solvent System Selection Strategies in Countercurrent Separation. Planta Med. 81, 1582-1591. doi: $10.1055 / \mathrm{s}-0035-1546246$

Locatelli, C., Filippin-Monteiro, F. B., Centa, A., and Creczinsky-Pasa, T. B. (2013). Antioxidant, antitumoral and anti-inflammatory activities of gallic acid. Handb. Gall. Acid Nat. Occur. Antioxid. Prop. Heal. Implic. Ed.). Nov. Publ., 1-23.

Luna, L., Simirgiotis, M. J., Lima, B., Bórquez, J., Feresin, G. E., and Tapia, A. (2018). UHPLC-MS metabolome fingerprinting: The isolation of main compounds and antioxidant activity of the andean species Tetraglochin ameghinoi (Speg.) Speg. Molecules 23, 793. doi: 10.3390/molecules23040793

Marston, A., and Hostettmann, K. (2006). Developments in the application of counter-current chromatography to plant analysis. J. Chromatogr. A 1112, 181-194. doi: 10.1016/j.chroma.2005.10.018

Martinez-Micaelo, N., González-Abuín, N., Ardèvol, A., Pinent, M., and Blay, M. T. (2012). Procyanidins and inflammation: Molecular targets and health implications. Biofactors 38, 257-265. doi: 10.1002/biof.1019

Mocan, A., Zengin, G., Simirgiotis, M., Schafberg, M., Mollica, A., Vodnar, D. C., et al. (2017). Functional constituents of wild and cultivated Goji ( L. barbarum L.) leaves: phytochemical characterization, biological profile, and computational studies. J. Enzyme Inhib. Med. Chem. 32, 153-168. doi: 10.1080/14756366.2016.1243535

Mølgaard, P., Holler, J. G., Asar, B., Liberna, I., Rosenbæk, L. B., Jebjerg, C. P., et al. (2011). Antimicrobial evaluation of Huilliche plant medicine used to treat wounds. J. Ethnopharmacol. 138, 219-227. doi: 10.1016/j.jep.2011.09.006

Muñoz, M., Barrera, E., and Meza, I. (1981). El uso medicinal y alimenticio de plantas nativas y naturalizadas en Chile. Mus. Nac. Hist. Nat. 33, 91.

Niu, X., Wang, Y., Li, W., Zhang, H., Wang, X., Mu, Q., et al. (2015). Esculin exhibited anti-inflammatory activities in vivo and regulated TNF- $\alpha$ and IL-6 production in LPS-stimulated mouse peritoneal macrophages in vitro through MAPK pathway. Int. Immunopharmacol. 29, 779-786. doi: 10.1016/ j.intimp.2015.08.041

Nwokocha, C., Palacios, J., Simirgiotis, M. J., Thomas, J., Nwokocha, M., Young, L., et al. (2017). Aqueous extract from leaf of Artocarpus altilis provides cardioprotection from isoproterenol induced myocardial damage in rats: Negative chronotropic and inotropic effects. J. Ethnopharmacol. 203, 163-170. doi: 10.1016/j.jep.2017.03.037

Petersson, G. A., Bennett, A., Tensfeldt, T. G., Al-Laham, M. A., Shirley, W. A., and Mantzaris, J. (1988). A complete basis set model chemistry. I. The total energies of closed-shell atoms and hydrides of the first-row elements. J. Chem. Phys. 89, 2193-2218. doi: 10.1063/1.455064

Qazi, S. S., Lombardo, D. A., and Abou-Zaid, M. M. (2018). A metabolomic and HPLC-MS/MS analysis of the foliar phenolics, flavonoids and coumarins of the Fraxinus species resistant and susceptible to emerald ash borer. Molecules 23, 2734. doi: $10.3390 /$ molecules 23112734

Quirantes-Piné, R., Funes, L., Micol, V., Segura-Carretero, A., and FernándezGutiérrez, A. (2009). High-performance liquid chromatography with diode array detection coupled to electrospray time-of-flight and ion-trap tandem mass spectrometry to identify phenolic compounds from a lemon verbena extract. J. Chromatogr. A 1216, 5391-5397. doi: 10.1016/j.chroma. 2009.05.038

Qureshi, A. A., Tan, X., Reis, J. C., Badr, M. Z., Papasian, C. J., Morrison, D. C., et al. (2011). Inhibition of nitric oxide in LPS-stimulated macrophages of young and senescent mice by $\delta$-tocotrienol and quercetin. Lipids Health Dis. 10, 239. doi: 10.1186/1476-511X-10-239

Re, R., Pellegrini, N., Proteggente, A., Pannala, A., Yang, M., and Rice-Evans, C. (1999). Antioxidant activity applying an improved ABTS radical cation decolorization assay. Free Radic. Biol. Med. 26, 1231-1237. doi: 10.1016/ S0891-5849(98)00315-3

Rodriguez, R., Marticorena, C., Alarcón, D., Baeza, C., Cavieres, L., Finot, V. L., et al. (2018). Catálogo de las plantas vasculares de Chile. Gayana. Botánica 75, 1-430. doi: 10.4067/S0717-66432018000100001

Sakushima, A., Ohno, K., Coskun, M., Seki, K. I., and Ohkura, K. (2002). Separation and identification of taxifolin 3-O-glucoside isomers from Chamaecyparis obtusa (Cupressaceae). Nat. Prod. Lett. 16, 383-387. doi: $10.1080 / 10575630290033141$ 
Salminen, J. P., Shikov, A. N., Karonen, M., Pozharitskaya, O. N., Kim, J., Makarov, V. G., et al. (2014). Rapid profiling of phenolic compounds of green and fermented Bergenia crassifolia L. leaves by UPLC-DAD-QqQ-MS and HPLC-DAD-ESI-QTOF-MS. Nat. Prod. Res. 28, 1530-1533. doi: 10.1080/ 14786419.2014.923999

Simirgiotis, M. J., Quispe, C., Bórquez, J., Mocan, A., and Sepúlveda, B. (2016). High resolution metabolite fingerprinting of the resin of Baccharis tola Phil. from the Atacama Desert and its antioxidant capacities. Ind. Crops Prod. 94, 368-375. doi: 10.1016/j.indcrop.2016.08.037

Skalicka-Woźniak, K., and Garrard, I. (2014). Counter-current chromatography for the separation of terpenoids: A comprehensive review with respect to the solvent systems employed. Phytochem. Rev. 13, 547-572. doi: 10.1007/s11101-014-9348-2

Takeda, Y., Isai, N., Masuda, T., Honda, G., Takaishi, Y., Ito, M., et al. (2001). Phlomisflavosides A and B, new flavonol bisglycosides from Phlomis spinidens. Chem. Pharm. Bull. 49, 1039-1041. doi: 10.1248/cpb.49.1039

Venditti, A., Guarcini, L., Ballero, M., and Bianco, A. (2015). Iridoid glucosides from Pentas lanceolata (Forssk.) Deflers growing on the Island of Sardinia. Plant Syst. Evol. 301, 685-690. doi: 10.1007/s00606-014-1106-9

Wu, X., Beecher, G. R., Holden, J. M., Haytowitz, D. B., Gebhardt, S. E., and Prior, R. L. (2004). Lipophilic and Hydrophilic Antioxidant Capacities of Common Foods in the United States. J. Agric. Food Chem. 52, 4026-4037. doi: 10.1021/jf049696w

Yang, D., Liu, S., Chen, Y., Hsu, S., Chang, Y., and Lin, J. (2015). Three pathways assess anti-inflammatory response of epicatechin with lipopolysaccharidemediated macrophage RAW 264.7 Cells. J. Food Biochem. 39, 334-343. doi: $10.1111 /$ jfbc. 12134
Yang, H., Yang, C., and Sun, T. (2018a). Characterization of glycopeptides using a stepped higher-energy C-trap dissociation approach on a hybrid quadrupole orbitrap. Rapid Commun. Mass Spectrom. 32, 1353-1362. doi: 10.1002/ $\mathrm{rcm} .8191$

Yang, Y., Zheng, K., Mei, W., Wang, Y., Yu, C., Yu, B., et al. (2018b). Antiinflammatory and proresolution activities of bergapten isolated from the roots of Ficus hirta in an in vivo zebrafish model. Biochem. Biophys. Res. Commun. 496, 763-769. doi: 10.1016/j.bbrc.2018.01.071

Zhang, Q. F., Guo, Y. X., Shangguan, X., Zheng, G., and Wang, W. J. (2013) Identification and quantification of Polyphenols in Rhizoma Smilacis Chinae by HPLC/DAD/ESI-MS/MS. J. Liq. Chromatogr. Relat. Technol. 36, 22512260. doi: $10.1080 / 10826076.2012 .720326$

Conflict of Interest: The authors declare that the research was conducted in the absence of any commercial or financial relationships that could be construed as a potential conflict of interest.

Copyright (C) 2020 Barrientos, Fernández-Galleguillos, Pastene, Simirgiotis, Romero-Parra, Ahmed and Echeverria. This is an open-access article distributed under the terms of the Creative Commons Attribution License (CC $B Y$ ). The use, distribution or reproduction in other forums is permitted, provided the original author(s) and the copyright owner(s) are credited and that the original publication in this journal is cited, in accordance with accepted academic practice. No use, distribution or reproduction is permitted which does not comply with these terms. 